\title{
Ocorrência de anticorpos contra o vírus Maedi-Visna em ovinos Santa Inês, no estado de Sergipe, Brasil
}

\author{
Occurrence of antibodies against Maedi-Visna in Santa Inês sheep in \\ the State of Sergipe, Brazil
}

\author{
Carlos Eduardo D’Alencar Mendonça ${ }^{1 *}$, Sílvia Letícia Bomfim Barros², Marcus Aurélio D’Alencar \\ Mendonça ${ }^{3}$, Vitor Andrade Accioly Guimarães ${ }^{4}$, Raymundo Rizaldo Pinheiro ${ }^{5}$
}

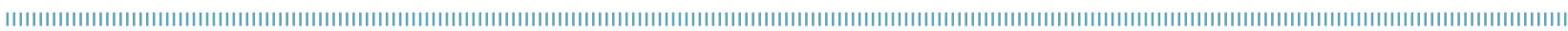

RESUMO: As Lentiviroses de Pequenos Ruminantes (LVPR) são enfermidades infecciosas de etiologia viral causadas por retrovírus, caracterizadas por uma doença de degeneração progressiva e lenta. O objetivo deste estudo foi determinar a ocorrência de anticorpos contra o lentivírus no rebanho ovino Santa Inês, de Sergipe. Para analisar o número mínimo de amostras utilizou-se o cálculo de Astudillo, com prevalência esperada $(p)$ de $10 \%$, margem de erro $(\alpha)$ de $20 \%$ e grau de confiança de $95 \%(g=1,96)$, obtendo-se o número mínimo de amostras $(n)$ de 861 . Foram colhidas 941 amostras de soro ovino oriundas de 54 propriedades e 19 municípios distribuídos nas três mesorregióes do Estado, sendo o número de amostras proporcional ao efetivo ovino do município. $\mathrm{O}$ soro foi acondicionado a $-20^{\circ} \mathrm{C}$ até a realização do teste de Imunodifusão em Gel de Ágar (IDGA). Os resultados considerados positivos ou suspeitos na IDGA foram reavaliados através da técnica de Western blotting. Dos animais amostrados, 194 (20,62\%) eram machos e 747 (79,38\%) eram fêmeas. Quanto à estratificação por idade, 300 ovinos eram jovens (31,88\%), entre seis meses e um ano, 308 (32,73\%) eram jovens adultos, entre 1 e 3 anos, e 333 (35,39\%) tinham idade estimada superior a 3 anos. Os resultados obtidos demonstraram que anticorpos contra o vírus Maedi-Visna (MVV) ocorrem no rebanho ovino do estado de Sergipe em baixa frequência $(0,11 \%)$. Assim, relata-se a ocorrência da infecção por Maedi-Visna em ovinos no estado de Sergipe e ressalta-se a participação do trânsito de animais na epidemiologia da doença.

PALAVRAS-CHAVE: epidemiologia; LVPR; Ovis aries; retrovírus.

\begin{abstract}
Small Ruminant Lentiviruses (SRLV) are infectious diseases of viral etiology caused by retroviruses, characterized for being a slowly progressive degenerative disease. The aim of this study was to determine the occurrence of antibodies against lentivirus in the flock of Santa Inês sheep in Sergipe, Brazil. A minimum number of samples was analyzed by the Astudillo calculation, with an expected prevalence $(p)$ of $10 \%$, error rate $(\alpha)$ of $20 \%$ and confidence level of $95 \%(g=1.96)$ obtaining the minimum number of samples (n) of 861. Finally, 941 serum samples were collected, derived from 54 properties and 19 municipalities distributed in three regions of the State, and the number of collected samples was proportional to the sheep flock of each municipality. The serum was placed at $-20^{\circ} \mathrm{C}$ until the Agar Gel Immunodiffusion test (AGID), and results considered as positive or suspicious in AGID were assessed by the Western blotting technique. Out of sampled animals, 194 (20.62\%) were male and 747 (79.38\%) were female. From the stratification by age, 300 were young sheep (31.88\%), aged between six months and one year old, $308(32.73 \%)$ were young adults, aged between 1 and 3 years old, and 333 (35.39\%) were estimated to be older than three years old. Results showed that antibodies against the Maedi-Visna virus in the sheep flock occurred in the State of Sergipe at low frequency $(0.11 \%)$. Thus, the occurrence of Maedi-Visna infection in sheep in the State of Sergipe is reported, and emphasizes the participation of the transit of animals in the epidemiology of the disease.
\end{abstract}

KEYWORDS: epidemiology; SRLV; Ovis aries; retroviruses.

\footnotetext{
'Programa de Pós-Graduação em Ciências Animais, Faculdade de Agronomia e Medicina Veterinária da Universidade de Brasília (UnB) - Brasília (DF), Brasil. ${ }^{2}$ Curso de Medicina Veterinária da Universidade Federal de Sergipe (UFS) - São Cristóvão (SE), Brasil.

${ }^{3}$ Programa de Pós-Graduação em Zoologia da Universidade Estadual de Santa Cruz (UESC) - Ilhéus (BA), Brasil.

${ }^{4}$ Programa de Pós-Graduação em Zootecnia da UFS - São Cristóvão (SE), Brasil.

${ }^{5}$ Empresa Brasileira de Pesquisa Agropecuária, Centro Nacional de Pesquisa em Caprinos e Ovinos - Sobral (CE), Brasil.

*Autor correspondente: carlos.mendonca@embrapa.br

Recebido em: 11/05/2012. Aceito em: 15/08/2013
} 
O vírus Maedi-Visna (MVV) compreende, juntamente com o vírus da Artrite Encefalite Caprina (CAEV), um grupo de retrovírus denominado cientificamente de Lentivírus de Pequenos Ruminantes (LVPR), sendo caracterizados por uma açáo patogênica lenta e pelo tropismo por células da linhagem monocítico-fagocitária de ovinos e caprinos (NARAYAN et al., 1997).

A enfermidade produzida pelos LVPR possui caráter crônico, gerando um quadro persistente e insidioso em decorrência da incapacidade do hospedeiro em desenvolver uma resposta imunitária eficiente (CAllado et al., 2001; BATISTA et al., 2004).

Animais infectados podem eliminar o vírus principalmente a partir de secreçóes pulmonares e por meio do leite contendo macrófagos infectados, transmitindo-o, desta forma, a animais suscetíveis, especialmente sob condiçôes de estreito contato, como aquelas observadas em sistemas de criação intensiva (SIMARD; Morley, i99i; Carey; Dalziel, 1993; Pinheiro et al., 2004; LeginAGOIKOA et al., 2006; SHULJAK, 2006).

A Maedi-Visna ainda é considerada uma doença sem tratamento ou vacina eficaz que possibilite seu efetivo controle. Dentre as LVPR, é relatada em várias partes do mundo com perdas econômicas significativas relacionadas às infecçóes, por vezes subestimadas (OIE, 2008). Os prejuízos causados afetam a produtividade, levam à desvalorização comercial dos animais e seus produtos ou, ainda, geram despesas com programas de controle (De La Concha-Bermejillo, 1997).

Atualmente, há planos para que as LVPR estejam inclusas no Programa Nacional de Sanidade dos Caprinos e Ovinos (PNSCO), do Ministério da Agricultura, Pecuária e Abastecimento (MAPA), ainda em fase de estruturaçáo (Brasil, 2007), entretanto, já constam na lista de doenças da Organização Mundial de Saúde Animal (OIE) e estáo sujeitas a embargos econômicos por países que seguem suas orientaçôes (OIE, 2008).

No Brasil, anticorpos contra o MVV foram diagnosticados em ovinos nos estados do Rio Grande do Sul (Dal Pizzol et al., 1989; Ribeiro, 1993), Paraná (Sotomaior; Milczewski, 1997), Rio Grande do Norte (Da Silva, 2003), Ceará (Araújo et al., 2004), Pernambuco (Oliveira et al., 2006), Tocantins (Moura Sobrinho et al., 2008), Bahia (Martinez et al., 2009), Espírito Santo (BARIoni et al., 2009) e São Paulo (Lombardi et al., 2009).

Não há registro de ocorrência da Maedi-Visna em Sergipe. Porém, este Estado é considerado berço da raça Santa Inês, e mantém relaçóes comerciais importantes com outras regióes do país adquirindo ou exportando ovinos, por isso é pouco provável que o rebanho local esteja livre desta enfermidade. Desta forma, este trabalho foi desenvolvido com o objetivo de estimar a frequência de ovinos sororreagentes para o MVV no Estado.

Para o desenvolvimento do estudo de frequência, foi realizado um cálculo de amostragem considerando os municípios com maiores efetivos ovinos em cada uma das três mesorregiôes sergipanas, delineando o espaço amostral da seguinte forma: mesorregião do Sertão de Sergipe (Nossa Senhora de Glória, Porto da Folha, Canindé do São Francisco, Poço Redondo, Gararu e Monte Alegre de Sergipe), mesorregião do Agreste de Sergipe (Lagarto, Tobias Barreto, Poço Verde, Itabaiana, Simão Dias e Campo do Brito) e mesorregiấo do Leste de Sergipe (Estância, Itabaianinha, Itaporanga d'Ajuda, Tomar do Geru, Salgado, São Cristóvão e Arauá) (Fig. 1), representando 78,23\% dos ovinos do Estado, cerca de 193.800 animais (SERGIPE, 2007).

Utilizou-se o cálculo de amostragem relacionado à prevalência de enfermidades infecciosas crônicas, desenvolvido por Astudillo (1979). Com base em estudos regionais (Silva, 2003; Araújo et al., 2004; Oliveira et al., 2006), a prevalência esperada $(p)$ foi definida em $10 \%$, admitindo-se margem de erro (a) de $20 \%$, com grau de confiança de $95 \%$ $(g=1,96): n^{\prime}=\mathrm{p}(100-\mathrm{p}) \mathrm{g}^{2} /(\mathrm{p} . \alpha / 100)^{2}$.

Tratando-se de um universo amostral (n) de 193.789 ovinos, utilizou-se o fator de correção para população finita: $\mathrm{n}=\mathrm{n}^{\prime} / 1+\left(\mathrm{n}^{\prime} / \mathrm{N}\right)$.

Desta forma, obteve-se um total de 861 amostras. No entanto, coletou-se um número superior de amostras em virtude da dificuldade de acesso às comunidades rurais e da possibilidade de imprevistos, que pudessem significar perda de amostras, totalizando 941 indivíduos amostrados.

A coleta das amostras foi aprovada pelo Comitê de Ética no Uso de Animais, com número de protocolo

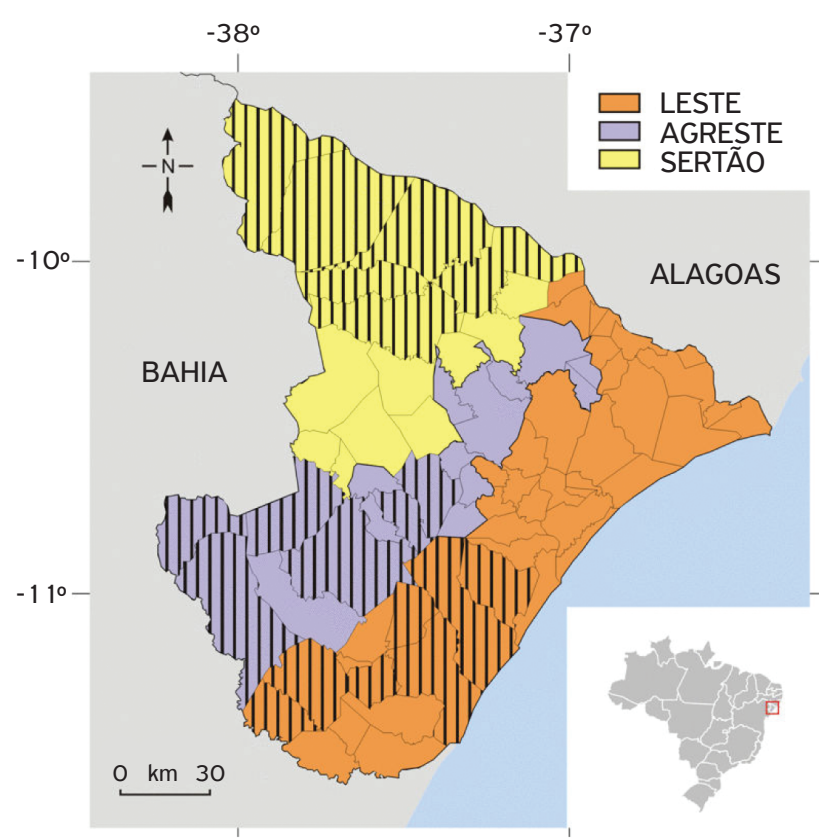

Figura 1. Mapa do estado de Sergipe com as divisões por mesorregiões (Sertão Sergipano, Agreste Sergipano e Leste Sergipano) e a identificação dos municípios avaliados (hachurados). No detalhe, a localização do estado de Sergipe no Brasil. 
(CEUA/UESC-39/2009). A partir da contençáo física dos ovinos, amostras sanguíneas foram coletadas através da punção da veia jugular externa, utilizando-se agulhas descartáveis $(25 \times 8 \mathrm{~mm})$ acopladas em tubos à vácuo sem anticoagulante, antecedida de assepsia local com álcool iodado a $2 \%$. Todas as amostras obtidas foram identificadas individualmente e segundo a propriedade de origem. Foram registradas informaçóes a respeito do sexo e idade estimada, de acordo com a avaliação da arcada dentária (STARke; Pretorius, 1955), além de características sobre a criação.

Apenas animais com idade superior a seis meses foram utilizados, considerando o tempo de soroconversão tardia característica ao vírus (Peterhans et al., 2004). A proporçáo de animais quanto ao sexo e à idade seguiu a estratificaçáo esperada do rebanho: $60 \%$ de matrizes, $30 \%$ de animais jovens e $10 \%$ de reprodutores.

Os soros foram obtidos por centrifugaçáo a $1.600 \mathrm{~g}$ por 10 minutos no Laboratório de Patologia Clínica do Hospital Veterinário "Dr. Vicente Borelli", da Faculdade Pio Décimo, no Sergipe, e, uma vez separados por aspiração, foram acondicionados em tubos tipo eppendorf e congelados a $-20^{\circ} \mathrm{C}$ até a análise. Os testes sorológicos foram realizados no Laboratório de Patologia Clínica do Centro Nacional de Pesquisa em Caprinos da Empresa Brasileira de Pesquisa Agropecuária (EMBRAPA Caprinos e Ovinos), em Sobral, no estado do Ceará.

Para a detecção de anticorpos contra o MVV, utilizou-se inicialmente a técnica de Imunodifusão em Gel de Ágar (IDGA), segundo Gouveia (2000), com uso do antígeno nacional produzido no Laboratório de Virologia da EMBRAPA Caprinos e Ovinos, a partir de sobrenadantes de células de membrana sinovial ovina (MSO) infectadas com o lentivírus ovino (cepa K-1514).

Os resultados considerados positivos ou suspeitos no IDGA foram reavaliados através da técnica de Western blot, empregando-se o mesmo antígeno viral purificado preparado através de ultracentrifugaçáo e colchão de sacarose (Pinheiro et al., 2006).

Foram coletadas amostras oriundas de 54 propriedades, distribuídas entre os 19 municípios de forma proporcional ao rebanho de cada um deles (Tabela 1).

Dos animais amostrados, 194 (20,62\%) eram machos e 747 (79,38\%) eram fêmeas. Quando considerada a estratificação por idade, 300 ovinos eram jovens $(31,88 \%)$, com idade entre seis meses e um ano, $308(32,73 \%)$ eram jovens adultos, entre 1 e 3 anos, e 333 (35,39\%) tinham idade estimada superior a três anos. Os resultados obtidos demonstraram que anticorpos para o MVV ocorreram em baixa frequência no rebanho ovino do estado de Sergipe $(0,11 \%)$, sendo encontrado somente um animal positivo, oriundo do município de Lagarto, localizado na mesorregiáo Agreste.

$\mathrm{O}$ animal positivo encontrado no presente trabalho, nascido na propriedade, apresentava idade superior a três anos e era utilizado como reprodutor devido às suas boas características zootécnicas. De forma geral, o rebanho ao qual pertencia apresentava um alto padrão genético, no qual os reprodutores eram criados em sistema intensivo, e as matrizes, em sistema semi-intensivo. Muitos dos

Tabela 1. Distribuição dos soros amostrados por propriedade nos municípios pesquisados no estado de Sergipe, 2008.

\begin{tabular}{|c|c|c|c|c|}
\hline Microrregião & Município & $\begin{array}{c}\text { Efetivo ovino do } \\
\text { Município }\end{array}$ & $\begin{array}{l}\text { Número de } \\
\text { Propriedades }\end{array}$ & $\begin{array}{c}\text { Número de soros } \\
\text { Amostrados }\end{array}$ \\
\hline \multirow{6}{*}{ Sertão } & Nossa Senhora da Glória & 33.880 & 9 & 143 \\
\hline & Porto da Folha & 12.167 & 3 & 53 \\
\hline & Canindé do São Francisco & 11.922 & 3 & 49 \\
\hline & Poço Redondo & 11.905 & 3 & 49 \\
\hline & Gararu & 7.166 & 2 & 31 \\
\hline & Monte Alegre de Sergipe & 6.688 & 2 & 32 \\
\hline \multirow{6}{*}{ Agreste } & Lagarto & 33.958 & 9 & 151 \\
\hline & Tobias Barreto & 22.748 & 6 & 111 \\
\hline & Poço Verde & 13.773 & 4 & 64 \\
\hline & Itabaiana & 7.343 & 2 & 39 \\
\hline & Simão Dias & 6.067 & 2 & 32 \\
\hline & Campo do Brito & 5.799 & 1 & 24 \\
\hline \multirow{7}{*}{ Leste } & Estância & 4.253 & 2 & 37 \\
\hline & Itabaianinha & 3.689 & 1 & 27 \\
\hline & Itaporanga d'Ajuda & 3641 & 1 & 25 \\
\hline & Tomar do Geru & 3.051 & 1 & 22 \\
\hline & Salgado & 2.250 & 1 & 18 \\
\hline & São Cristóvão & 1.914 & 1 & 19 \\
\hline & Arauá & 1.575 & 1 & 15 \\
\hline Total & & 193.789 & 54 & 941 \\
\hline
\end{tabular}


animais participavam frequentemente de exposiçóes agropecuárias dentro e fora do Estado.

Diversos estudos epidemiológicos das LVPR têm demonstrado a disseminação dos lentivírus em vários estados, sendo que um dos fatores que tem contribuído para isso é a prática de melhoramento genético utilizando raças exóticas (Almeida et al., 2001; Pinheiro et al. 2001; 2004).

A ocorrência de Maedi-Visna observada no presente trabalho $(0,11 \%$ - 1/941) foi mais baixa que as relatadas em rebanhos ovinos do Rio Grande do Sul (10,5\%: DAL Pizzol et al., 1989; 19,0\%: Ribeiro, 1993), Rio Grande do Norte (21,3\%: DA Silva, 2003), São Paulo (2,7\%: Lombardi et al., 2009), Tocantins (0,9\%: Moura Sobrinho et al., 2008) e Bahia (0,5\%: Souza et al., 2007; 0,3\%: Martinez et al., 2009). Porém, foi superior ao resultado encontrado em Botucatu, SP, de 0,0\% (Rosa et al., 2009).

Quando comparados a estudos realizados apenas com animais da raça Santa Inês, obteve-se frequência sorológica inferior à descrita em Fortaleza por Araújo et al. (2004), que relataram uma prevalência de 4,93\%, em Pernambuco, por Oliveira et al. (2006), que encontraram 3,8\%, e da Costa et al. (2007), que encontraram soropositividade de $2,2 \%$ e de 1,07\%, separadamente, para as regióes Agreste e Sertão respectivamente. No Espírito Santo, BARIONI et al. (2009) obtiveram 7,33\%.

A contaminação do indivíduo positivo pode ter ocorrido durante sua participação em feiras de exposiçóes de

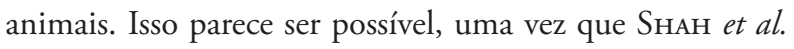
(2004) detectaram a ocorrência de infecção em 68 ovinos oriundos de propriedades livres de lentiviroses após participarem de uma feira agropecuária na Suíça, onde foram mantidos em contato com outros ovinos e caprinos, espécie da qual também admite-se a possibilidade de transmissão.

Sugere-se também a possibilidade de a infecção ter ocorrido por contato entre animais em centrais de inseminação. $\mathrm{O}$ espécime infectado foi utilizado em centrais nos estados do Rio de Janeiro e da Bahia, onde a infecção por LVPR já foi relatada (Assis, 1993).

Segundo Sнан et al. (2004), parece não existirem dúvidas de que caprinos podem não apenas se infectar com o MVV, como também transmiti-lo para ovinos, mas, apesar da manutençáo de caprinos na propriedade em questáo e de sua utilizaçáo para aleitamento artificial de ovinos em casos especiais, esta via de infecção mostra-se improvável neste caso, uma vez que as duas espécies eram criadas separadamente, e o animal sororreagente recebeu apenas aleitamento materno.

Embora a transmissão do vírus possa ocorrer por secreçôes respiratórias, considerada uma das principais rotas de infecção (CAREy; DAlziel, 1993), o fato de os reprodutores serem criados em sistema de confinamento pode ter dificultado a propagaçáo do agente para os demais animais do rebanho.

$\mathrm{O}$ animal positivo não apresentou alteraçóes clínicas, o que pode ser explicado pelo Maedi-Visna se caracterizar por longo período de incubação, curso clínico demorado e lentamente progressivo, apresentando-se, na maioria das vezes, na forma inaparente (Brodie, 1998; Moojen, 2001).

Ainda que uma interpretação cautelosa seja indicada nos casos de baixas prevalências, salienta-se que a probabilidade de ocorrência de resultados falso-negativos no IDGA é maior que a de falso-positivos, já que este teste apresenta alta especificidade (OIE, 2008). Além disso, o IDGA aplicado nesta pesquisa detecta as proteínas virais p28 e gp135, que têm sido correlacionadas a aprimoramentos da capacidade de detecção da técnica, aumentando a sensibilidade do teste (Ayelet et al., 2001), além da confirmação pelo Western blot.

Devido à baixa soropositividade encontrada, não foi possível avaliar estatisticamente fatores associados à infecção, pois, segundo Katz (2003), seriam necessárias no mínimo cerca de 10 amostras positivas para cada variável a ser analisada.

O Maedi-Visna está presente no rebanho de ovinos Santa Inês no estado de Sergipe com baixa frequência. Desta forma, sugere-se a implantação de rigoroso programa de controle para evitar a disseminação da enfermidade.

\section{AGRADECIMENTOS}

À Empresa Brasileira de Pesquisa Agropecuária, Centro Nacional de Pesquisa em Caprinos e Ovinos, por proporcionar a realização das análises laboratoriais. Ao Sr. Josino Carlos Farias de Mendonça, pelo custeio das viagens e material necessário para coleta das amostras. 


\section{REFERÊNCIAS}

ALMEIDA, M.G.A.R.; ANUNCIAÇÃO, A.V.M.; FIGUEIREDO, A.; MARTINEZ, T.C.N.; LABORDA, S.S. Dados sorológicos sobre a presença e distribuição da artrite-encefalite caprina (CAE) no Estado da Bahia, Brasil. Revista Brasileira de Saúde e Produção Animal, v.1, n.3, p.78-83, 2001.

ARAÚJO, S.A.; DANTAS, T.V.M.; TEIXEIRA, M.F.S. Levantamento sorológico de Maedi-Visna em ovinos de abatedouro da Região Metropolitana de Fortaleza-CE. In: CONGRESSO BRASILEIRO DE MEDICINA VETERINÁRIA, 31., 2004, São Luis. Resumos... São Luis, 2004. [CD-ROOM]

ASSIS, A.P.M.V. Evidência sorológica da ocorrência de lentivírus (Maedi Visna/Artrite Encefalite Caprina) em rebanhos nos Estados de Minas Gerais, Rio de Janeiro, Bahia e Ceará de 1991 a 1993. 1993. 61 f. Dissertação (Mestrado em Medicina Veterinária) Escola de Medicina Veterinária, Universidade Federal de Minas Gerais, Belo Horizonte.

ASTUDILLO, V.M. Encuestas por muestreo para estudios epidemiológicos en populaciones animals. Rio de Janeiro: Centro Panamericano de Febre Aftosa, 1979. p.35. (Série de Manuales Didáticos n 12)

AYELET, G.; ROGER, F.; TIBBO, M.; TEMBELY, S. Survey of MaediVisna (MV) in Ethiopian Highland Sheep. The Veterinary Journal, v. 161, n.2, p.208-210, 2001.

BARIONI, G.; PEREIRA, L.V.; BELTRAME, M.A.V.; TESOLINE, P.; GUMIEIRO, M.V. Soroprevalência de Maedi-Visna em ovinos da raça Santa Inês nos municípios da grande Vitória - ES. In: CONGRESSO BRASILEIRO DE BUIATRIA, 8., 2009, Belo Horizonte, MG. Anais. Belo Horizonte, 2009. p.579-584.

BATISTA, M.C.S.; CASTRO, R.S.; CARVALHO, F.A.A.; CRUZ, M.S.P.; RÊGO, E.W.; SILVA, S.M.M.S.; OLIVEIRA, R.A.; LOPES, J.B. Pesquisa de anticorpos anti-lentivírus de pequenos ruminantes em ovinos, no Estado do Piauí, Brasil. In: CONGRESSO BRASILEIRO DE MEDICINA VETERINÁRIA, 31 ., 2004, São Luis, MA. Resumos... São Luis, 2004. [CD-ROOM].

BRASIL. Ministério da Agricultura Pecuária e Abastecimento. Instrução Normativa № 87, de 10 de dezembro de 2004. Aprova o Regulamento Técnico do Programa Nacional de Sanidade dos Caprinos e Ovinos. Disponível em: <http://extranet.agricultura. gov.br/sislegis-consulta/consultarLegislacao.do?operacao $=\mathrm{vi}$ sualizar\&id=10454>. Acesso em: 04 abril 2007.

BRODIE, S.J.; de la CONCHA-BERMEJILLO, A.; SNOWDER, G.D.; DeMARTINI, J.C. Current concepts in the epizootiology, diagnosis, and economic importance of ovine progressive pneumonia in North America: A review. Small Ruminant Research, v.27, n.1, p.1-17, 1998.

CALLADO, A.K.C.; CASTRO, R.S.; TEIXEIRA, M.F.S. Lentivírus de Pequenos Ruminantes (CAEV e Maedi-Visna): Revisão e perspectivas. Pesquisa Veterinária Brasileira, v.21, n.3, p.87-97, 2001.
CAREY, N.; DALZIEL, R.G. The biology of Maedi-Visna virus - an overview. British Veterinary Journal, v. 149 , n.5, p.437-454, 1993.

Da COSTA, L.S.P.; De LIMA, P.P.; CALLADO, A.K.C.; Do NASCIMENTO, S.A.; De CASTRO, R.S. Lentivírus de pequenos ruminantes em ovinos Santa Inês: isolamento, identificação pela PCR e inquérito sorológico no estado de Pernambuco. Arquivos do Instituto Biológico, v.74, n.1, p.11-16, 2007.

Da SILVA, J.B.A. Levantamento sorológico pelo teste de imunodifusão em gel de agarose (IDGA) da lentivirose ovina em rebanhos do Rio Grande do Norte, Brasil. 2003. 58f. Dissertação (Mestrado em Medicina Veterinária) - Faculdade de Veterinária, Universidade Estadual do Ceará, Fortaleza.

Dal PIZZOL, M.; RAVAZZOLO, A.P.; GONÇALVES I.P.D.; HOTZEL, I.; FERNANDES, J.C.T.; MOOJEN, V. MAEDI-VISNA: identificação de ovinos infectados no Rio Grande do Sul, Brasil, 1987-1989. Arquivos da Faculdade de Veterinária da UFRGS, v.17, p.65-76, 1989.

DE LA CONCHA-BERMEJILLO, A. Maedi-Visna and ovine progressive pneumonia. Veterinary Clinics North America: Food Animal Practice, v.13, n. 1, p.13-33, 1997.

GOUVEIA, A.M.G.; MELO, L.M.; PIRES, L.L.; PINHEIRO, R.R. Microimunodifusão em gel de ágar para o diagnóstico sorológico de infecção por lentivírus de pequenos ruminantes. In: CONGRESSO BRASILEIRO DE MEDICINA VETERINÁRIA, 27. 2000, Águas de Lindóia, SP. Resumos... Áquas de Lindóia, p.33.

KATZ, M.H. Multivariable Analysis: A Primer for Readers of Medical Research. Annals of Internal Medicine, v.138, p.644650, 2003.

LEGINAGOIKOA, I.; JUSTE, R.A.; BARANDIKA, J.; AMORENA, B.; De ÁNDRES, D.; LUJÁN, L.; BADIOLA, J.; BERRIATUA, E. Extensive rearing hinders Maedi-Visna Virus (MVV) infection in sheep. Veterinary Research, v.37, p.767-778, 2006.

LOMBARDI, A.L.; NOGUEIRA, A.H.C.; FERES, F.C.; PAULO, H.P.; CASTRO, R.S.; FEITOSA, F.L.P.; CADIOLI, F.A.; PEIRÓ, J.R.; PERRI, S.H.V.; LIMA, V.F.M.; MENDES, L.C.N. Soroprevalência de Maedi-Visna em ovinos na região de Araçatuba, SP. Arquivo Brasileiro de Medicina Veterinária e Zootecnia, v.61, n.6, p. 1434-1437, 2009

MARTINEZ, P.M.; COSTA, J.N.; SOUZA, T.S.; ANUNCIAÇÃO, T.V.M.; PINHEIRO, R.R. Anticorpos contra o vírus da maedivisna em rebanhos ovinos da microrregião de Juazeiro - Bahia. In: CONGRESSO BRASILEIRO DE BUIATRIA, 8., 2009, Belo Horizonte, MG. Anais. Belo Horizonte, 2009, p.603-608.

MOOJEN, V. Maedi-Visna dos ovinos. In: RIET-CORRÊA, F. Doenças de Ruminantes e Eqüinos. São Paulo: Varela, 2001. v.1, p.138-144. 
MOURA SOBRINHO, P.A.; FERNANDES, C.H.C.; RAMOS, T.R.R.; CAMPOS, A.C.; COSTA, L.M.; CASTRO, R.S. Prevalência e fatores associados à infecção por lentivírus de pequenos ruminantes em ovinos no estado do Tocantins. Ciência Veterinária nos Trópicos, v.11, n.2/3, p.65-72, 2008.

NARAYAN, O.; JOAG, S.V.; CHEBLOUNE, Y.; ZINK, M.C.; CLEMENTS, J.E. Visnamaedi: the prototype lentiviral disease. In: Nathanson, N. (Ed.). Viral Pathogenesis. Philadelphia: LippincottRaven Publishers, 1997. p.657- 668.

OIE. World Organization for Animal Health. Arttritis/encefalitis caprina y Maedi-Visna. Manual de la OIE sobre animales terrestres 2008. 983 p. Disponível em: <http://web.oie. int/esp/normes/mmanual/pdf_es_2008/2.07.03-04.\%20 Artritis-Encefalitis\%20caprina\%20y\%20Maedi\%20Visna. pdf $>$. Acesso em: 17 nov. 2008.

OLIVEIRA, M.M.M.; CASTRO, R.S.; CARNEIRO, K.L.; NASCIMENTO, S.A.; CALLADO, A.K.C.; ALENCAR, C.S.A.; COSTA, L.S.P. Anticorpos. Anticorpos contra lentivírus de pequenos ruminantes em caprinos e ovinos em abatedouros do estado do Pernambuco. Arquivo Brasileiro de Medicina Veterinária e Zootecnia, v.58, n.5, p.947-949, 2006.

PETERHANS, E.; GREENLAND, T.; BADIOLA, J.; HARKISS, G.; BERTONI, G.; AMORENA, B.; ELIASZEWICZ, M.; JUSTE, R.A.; KRAßNIG, R.; LAONT, J.P.; LENIHAN, P.; PÉTURSSON, G.; PRITCHARD, G.; THORLEY, J.; VITU, C.; MORNEX, J.F.; PÉPIN, $M$. Routes of transmission and consequences of small ruminant lentiviruses (SRLVs) infection and erradication schemes. Veterinary Research, v.35, p.257-274, 2004.

PINHEIRO, R.R.; GOUVEIA, A.M.G.; ALVES, F.S.F.; ANDRIOLI, A. Perfil de propriedades no estado do Ceará relacionado à presença do lentivírus caprino. Ciência Animal, v.14, n.1, p.2937, 2004.

PINHEIRO, R.R.; GOUVEIA, A.M.G.; ALVES, F.S.F. Prevalência da infecção pelo vírus da Artrite Encefalite Caprina no Estado do Ceará, Brasil. Ciência Rural, v.31, n.3, p.449-454, 2001.

PINHEIRO, R.R.; OLORTEGUI, C.C.; GOUVEIA, A.M.G.; ARAUJO, S.C.; ANDRIOLI, A. Desenvolvimento de dot-blot para detecção de anticorpos para o vírus da Artrite Encefalite Caprina. Revista Portuguesa de Ciências Veterinárias, v.101, p.51-56, 2006.

RIBEIRO, L.A. Risco da introdução de doenças exóticas pela importação de ovinos. Boletim do Laboratório Regional de Diagnóstico, n.13, p.39-44, 1993.

ROSA, E.P.; AMORIM, R.M.; FERREIRA, D.O.L.; CHIACCHIO, S.B.; MODOLO, J.R. Soroprevalência da pneumonia progressiva ovina Maedi-Visna na região de Botucatu, SP. Ciência Animal Brasileira, v.10, n.3, p.847-852, 2009.

SERGIPE (Estado). Secretaria Estadual de Desenvolvimento Agropecuário de Sergipe, Empresa de Desenvolvimento Agropecuário do Estado de Sergipe (EMDAGRO). SIDEAGRO: Sistema de Cadastro Agrícola. Aracaju, SE, 2007.

SHAH, C.; HUDER, J.B.; BÖNI, J.; SCHÖNMANN, M.; MÜHLHERR, J.; LUTZ, H.; SCHÜPBACH, J. Phylogenetic analysis and reclassification of caprine and ovine lentiviruses based on 104 new isolates: evidence for regular sheep to goat transmission and world propagation through liverstock trade. Virology, v.319, p.12-26, 2004.

SHULJAK, B.F. Lentiviruses in ungulates: I. general features, history and prevalence. Bulgarian Journal of Veterinary Medicine, v.9, n.3, p.175-181, 2006.

SIMARD, C.; MORLEY, R.S. Seroprevalence of Maedi-Visna in Canadian sheep. Canadian Journal of Veterinary Research, v.55, n.3, p.269-273, 1991.

SOTOMAIOR, C.; MILCZEWSKI, V. Relato de um rebanho ovino infectado pelo vírus Maedi-Visna no Estado do Paraná. In: CONGRESSO BRASILEIRO DE MEDICINA VETERINÁRIA, 25, 1997, Gramado, RS. Resumo... Gramado, 1997. p.179.

SOUZA, T.S.; COSTA, J.N.; MARTINEZ, P.M.; PINHEIRO, R.R. Estudo. Estudo sorológico da Maedi-Visna pelo método da imunodifusão em gel de ágar em rebanhos ovinos de Juazeiro, Bahia, Brasil. Revista Brasileira de Saúde e Produção Animal, v.8, n.4, p.276-282, 2007.

STARKE, J.S.; PRETORIUS, A.G. Dentition of sheep as indication of age. Farming in South Africa, v.30, p.53-56, 1955. 